\title{
CHARACTERISTICS OF STABLE ISOTOPES IN GLACIERS \\ IN THE HIGH MOUNTAINS OF CHINA \\ Abstract
}

by

WU XIaoling and Xie Zichu

Lanzhou Institute of Glaciology and Cryopedology, Academia Sinica, Lanzhou, Gansu, People's Republic of China

HISAO WUSHIKU

Tokyo Technology Institute, Tokyo, Japan

\section{NOBUKO KANAMORI}

Water Research Institute, Nagoya University, Nagoya, Japan

For the study of glacier nourishment and hydrological characteristics in the high mountainous regions of China, measurements of deuterium and oxygen-18 isotope composition and determination of $\mathrm{F}^{-}, \mathrm{Cl}^{-}, \mathrm{SO}_{4}^{2-}, \mathrm{NO}_{3}^{-}$, were carried out. 98 samples of ice core, glacial meltwater, snow, and ice were collected from mountainous regions of Tian Shan, Qilian Shan, Qomolangma and Tibet Plateau during glaciological expeditions, mainly in 1978-1980.

Results of isotope composition and determination of anions of all samples are presented and discussed as follows:

1) The distribution of glacial isotope contents reflects the altitude effect of isotope (lower $\delta$ at higher altitude), $\delta$ (D) is respectively -160 to $-210 \%,-95$ to $-147 \%,-56$ to $-65 \%$, and -54 to $-71 \%$ in the Mt Qomolangma area $(6700 \mathrm{~m}$ a.s.l.), western and eastern parts of Qilian Shan, and Tian Shan area.

2) A study of ice annual layers in the accumulation area of Glacier no. 1 in Tian Shan (4075 m a.s.1.) was carried out. Its result shows a seasonal effect of isotope ( $\delta 5$ lower in winter than in summer). Within $4.5 \mathrm{~m}$ depth of glacial profile 6 annual layers were distinguished.

3) The stable isotope contents of different types in ice and snow (new snow, granular snow, depth hoar, dirt layer and metamorphosed ice, etc) also indicate an isotopic effect.

4) Daily variations of isotope contents and anion composition of glacial meltwater or meltwater originating from mountains covered by several glaciers are contolled mainly by the meltwater contribution to river flow, relative to precipitation and ground water.

5) This paper also deals with the $\delta$ (D) and $\delta\left({ }^{18} \mathrm{O}\right)$ relationship, and for the first time a linear formula is given showing the relationship between $\delta$ (D) and $\delta\left({ }^{18} \mathrm{O}\right)$ for the glacial isotope contents of high mountainous regions in China, so that all the deuterium or oxygen-18 contents of ice, snow and water can be read in terms of $\delta\left({ }^{18} 0\right)$ using this linear relationship.

\section{INTERNAL FREEZING OF SNOW COVER DUE TO ITS OWN COLD HEAT SOURCES \\ Abstract}

by

\section{Y YAMADA AND T IKARASHI}

Institute of Snow and Ice Studies, National Research Center for Disaster Prevention, Nagaoka, Niigata-ken, Japan 940

This report discusses the one-dimensional freezing of dry snow/ wet snow systems for the condition first examined by Stefan: the problem of heat conduction with phase change. There are two systems of internal freezing: one is a closed system of temperature rise in a dry snow layer sandwiched between upper and lower wet snow layers; the other an open system of freezing of a thin wet layer provoked mainly by an upper dry snow layer facing the atmosphere at its surface. The latter negatively concerns the release of some avalanches, because the weak layers of surface avalanches in districts where the melt-freeze metamorphism prevails (as in the Horuriku district of Japan) may be the thin wet granular snow layers.

Numerical results are given for different conditions of internal freezing. A comparison with field observations reveals the fundamental aspect of this phenomenon and the possibility of avalanche release. 